\title{
Fluorescent Proteins Expressed in Mouse Transgenic Lines Mark Subsets of Glia, Neurons, Macrophages, and Dendritic Cells for Vital Examination
}

\author{
Yi Zuo, ${ }^{1 \star}$ Jane L. Lubischer, ${ }^{1 \star}$ Hyuno Kang, ${ }^{1 \star}$ Le Tian, ${ }^{1 \star}$ Michelle Mikesh, ${ }^{1}$ Alexander Marks, ${ }^{4}$ Virginia L. Scofield, ${ }^{3}$ \\ Shan Maika, ${ }^{2}$ Craig Newman, ${ }^{1}$ Paul Krieg, ${ }^{5}$ and Wesley J. Thompson ${ }^{1}$ \\ ${ }^{1}$ Section of Neurobiology, Institute for Neuroscience, Institute for Cellular and Molecular Biology, and ${ }^{2}$ Mouse Genetic Engineering Facility, University of \\ Texas, Austin, Texas 78712, ${ }^{3}$ University of Texas M.D. Anderson Cancer Center, Smithville, Texas 78957, ${ }^{4}$ Banting and Best Department of Medical \\ Research, University of Toronto, Toronto, Ontario, M5G 1L6 Canada, and 5Department of Cell Biology and Anatomy, University of Arizona College of \\ Medicine, Tucson, Arizona 85724
}

To enable vital observation of glia at the neuromuscular junction, transgenic mice were generated that express proteins of the green fluorescent protein family under control of transcriptional regulatory sequences of the human S100B gene. Terminal Schwann cells were imaged repetitively in living animals of one of the transgenic lines to show that, except for extension and retraction of short processes, the glial coverings of the adult neuromuscular synapse are stable. In other lines, subsets of Schwann cells were labeled. The distribution of label suggests that Schwann cells at individual synapses are clonally related, a finding with implications for how these cells might be sorted during postnatal development. Other labeling patterns, some present in unique lines, included astrocytes, microglia, and subsets of cerebellar Bergmann glia, spinal motor neurons, macrophages, and dendritic cells. We show that lines with labeled macrophages can be used to follow the accumulation of these cells at sites of injury.

Key words: neuromuscular junction; Schwann cell; microglia; Langerhans cell; astrocyte; S100 $\beta$; S100B; motor neuron; variegation; Bergmann glia

\section{Introduction}

Fluorescent proteins of the green fluorescent protein (GFP) family have revolutionized our ability to image cells in living organisms (Chalfie et al., 1994). By coupling nucleotide sequences encoding fluorescent proteins to cell-specific promoters, transgenes have been constructed that make specific cell types in living organisms fluorescent. As a consequence of incomplete promoters or random integration, expression of these transgenes can be limited to subsets of a particular cell type (cf. Feng et al., 2000) or occur in unexpected cell types. Because this variegation is generally consistent within animals of the same transgenic line, a small number of labeled cells of a particular type can be examined in each line. For example, variegation in the expression of fluores-

\footnotetext{
Received Aug. 17, 2004; revised 0ct. 29, 2004; accepted Nov. 3, 2004.

This work was supported by National Institutes of Health Grants NS20480 (W.J.T.) and HL63926 (P.K.). We thank Mendell Rimer and Chris Hayworth for a critical reading of this manuscript and John Klein for discussions.

*Y.Z., J.L.L., H.K., and L.T. contributed equally to this work.

Correspondence should be addressed to Wesley J. Thompson, Section of Neurobiology C0920, University of Texas, Austin, TX 78712. E-mail:wes@mail.utexas.edu.

J. L. Lubischer's present address: Department of Zoology, North Carolina State University, CB7617, Raleigh, NC 27695.

L. Tian's present address: Department of Physiology and Biophysics, University of Washington, Seattle, WA 98195.

C. Newman's present address: Department of Biochemistry, College of Agricultural and Life Sciences, University of Wisconsin, Madison, WI 53706.

DOI:10.1523/JNEUROSCI.3934-04.2004

Copyright $\odot 2004$ Society for Neuroscience $\quad$ 0270-6474/04/2410999-11\$15.00/0
}

cent proteins driven by the thy 1.1 promoter has enabled repeated visualization of individual neurons in the cortex of mice and provided information about the dynamism of synapses in the adult brain (Grutzendler et al., 2002; Trachtenberg et al., 2002; Mizrahi et al., 2004). Similarly, expression of different colored fluorescent proteins in subsets of motor neurons has enabled detailed study of the competition occurring at neuromuscular junctions (NMJs) during neonatal synapse elimination (Walsh and Lichtman, 2003).

Terminal Schwann cells (TSCs), glial cells that cap the nerve terminal at the NMJ, play roles in maintaining and modulating this synapse (Robitaille, 1998; Reddy et al., 2003) and facilitate its repair after nerve injury (Son and Thompson, 1995a,b; Koirala et al., 2000). Vital imaging of nerve terminals and postsynaptic receptors in muscles has been successfully used to obtain new insights into the stability and plasticity of NMJs (Rich and Lichtman, 1989; Balice-Gordon and Lichtman, 1990, 1993, 1994; Walsh and Lichtman, 2003), and we wished to expand such observations to include TSCs. Other investigators have used antibodies or lectins that bind to cell surface components of Schwann cells and/or the extracellular matrix they deposit (Astrow et al., 1998) or have labeled Schwann cells with AM esters of fluorescent compounds that, for unknown reasons, give selective labeling of TSCs (O’Malley et al., 1999). These approaches have drawbacks, including difficulties in distinguishing the cells from their matrix and unreliable cell labeling. To circumvent these problems, we 
prepared transgenic mice expressing fluorescent proteins in their Schwann cells. The protein $\mathrm{S} 100 \mathrm{~B}$, previously known as $\mathrm{S} 100 \beta$, is a commonly used marker for glial cells (cf. Ludwin et al., 1976; Stefansson et al., 1982), and elements of its promoter have been characterized and shown to drive expression in stably transfected glial cells in vitro (Allore et al., 1990; Jiang et al., 1993; Castets et al., 1997). We coupled human-S100B upstream sequences to sequences coding for fluorescent proteins and prepared transgenic mice. A number of stable lines of mice were generated that selectively label TSCs. We show here that we can repeatedly image these cells in living, adult mice and that TSCs, like the nerve terminals they cover, are mostly stable. In addition, some of the lines showed labeling of subsets of Schwann cells. We used these subset lines to examine the mix of labeled and unlabeled Schwann cells at individual junctions. The nonrandom distribution of labeled cells suggests how Schwann cells come to populate junctions during development. Last, we have examined other cells labeled in these mice. We find that some of the expression patterns are predicted by the endogenous expression of S100B, whereas others are not. These transgenic lines offer the opportunity to study in a vital manner particular subsets of glia, neurons, and antigenpresenting cells of the immune system.
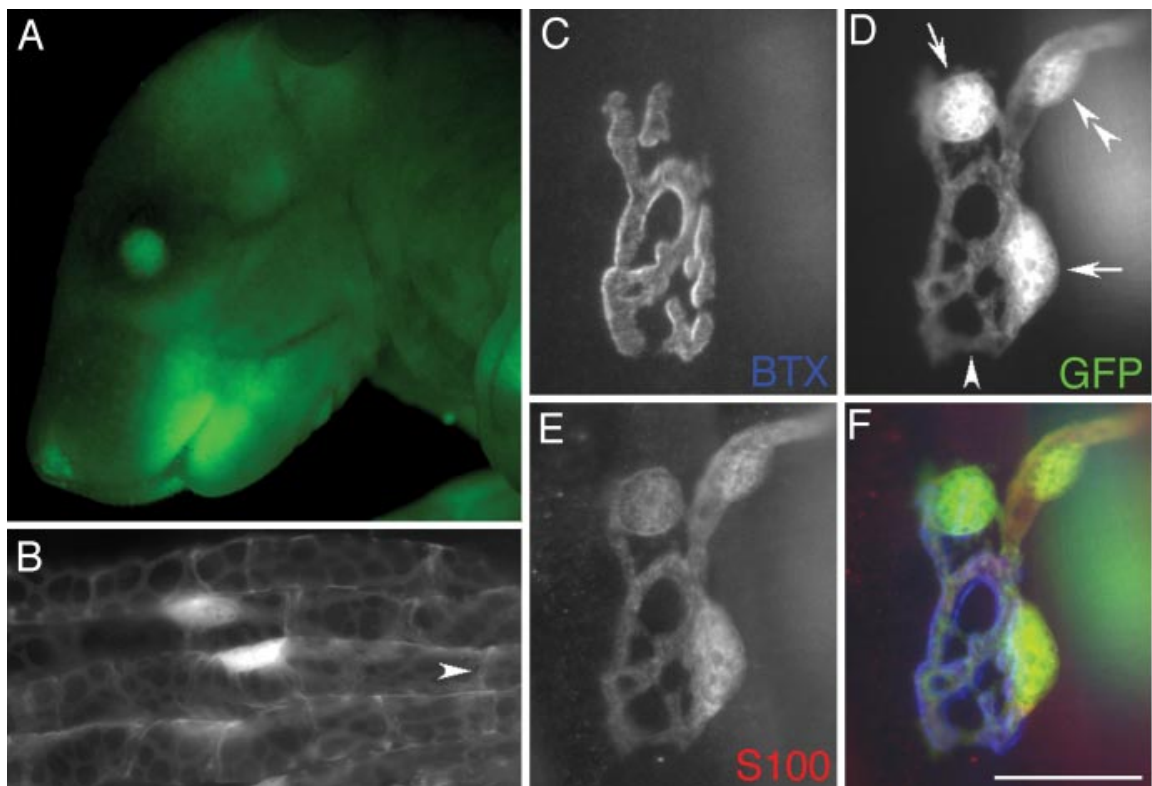

Figure 1. GFP in the Kosmos line is visible in the intact animal and in myelinating and terminal Schwann cells. $A$, Fluorescence image of a mouse pup of the Kosmos line showing GFP in the eyes and skin, caused by expression in the lens and Langerhans cells, respectively. Such fluorescence is present in all FP lines generated, even in adults, although that in the skin becomes hidden by hair. Expression in the bones can also be seen through the skin of neonates. $B$, Four myelinated axons in an intramuscular nerve of a sternomastoid muscle in an adult mouse. Cell bodies of the myelinating Schwann cells are brightly fluorescent, as are thickened ribbons of cytoplasm on the abaxonal surface of the myelin wrappings. An arrowhead identifies a Schmidt-Lanterman incisure. $(-F, N M J$ in a sternomastoid muscle after fixation and labeling with two fluorophore reagents. AChRs labeled with Cy5conjugated $\alpha$-bungarotoxin (C, BTX) lie in pretzel-shaped synaptic gutters occupied by branches of the nerve terminal not labeled here. D, GFP in Schwann cells. E, Labeling of the Schwann cells with antibody to $S 100$ and a rhodamine secondary antibody. $F$, Merged image with receptors pseudocolored blue, $\mathrm{S} 100$ red, and GFP green. The same structures labeled by anti-S100 are labeled by GFP, including cell bodies of TSCS ( $D$, arrows), processes of TSC $S$, and the $S$ chwann cell ( $D$, double arrowhead) wrapping the last myelinated internode of the axon innervating the junction. The processes of the TSCs match the underlying receptors, except in cases where they link adjacent gutters (D, arrowhead). Similar GFP labeling was present in all muscles examined in the Kosmos line. Scale bar: $B, 30 \mu \mathrm{m} ; C-F, 20 \mu \mathrm{m}$.

\section{Materials and Methods}

Construction of transgenes and generation of transgenic mice. Using a combination of restriction endonuclease fragment isolation and PCR amplification, $9.4 \mathrm{~kb}$ of human S100B regulatory sequence was inserted upstream of the enhanced GFP (EGFP) coding region in pEGFP-1 (Clontech, Cambridge, UK; BD Biosciences, Franklin Lakes, NJ) or enhanced yellow fluorescent protein (EYFP) coding region in pEYFP-1 (Clontech). In both cases the vectors were modified by alteration of the AflII site at the end of the SV40 polyadenylation module to a PmeI site. The human sequences include $6.6 \mathrm{~kb}$ of $5^{\prime}$ flanking sequence, the first noncoding exon of $71 \mathrm{nt}$ and $2.7 \mathrm{~kb}$ of intron 1 , including the $3^{\prime}$ splice acceptor site. The $\sim 10.4 \mathrm{~kb}$ transgene was isolated from vector backbone sequences by digestion with restriction endonucleases SacII and PmeI and gel-purified. Transgenic mice were generated using standard techniques previously described (Hogan et al., 1994). Briefly, C57BL/6 X DBA (F2) zygotes were injected with the transgenes and subsequently transferred into the oviducts of pseudopregnant CD1 females. After genotyping (or phenotyping in the case of the YFP mice), resulting founders were bred to C57BL/6 X DBA (F1) mice to establish and maintain lines.

Our first attempts used an S100-GFP transgene. By Southern blotting and PCR, six potential founders were identified from a total of 40 animals injected as embryos, and five of these were found to have germline integration of the transgene. Animals of one of these five F1 lines showed no detectable expression of GFP, and this line was discarded. Offspring of the remaining four founders showed GFP expression in Schwann cells located in the intramuscular nerves and overlying NMJs. Of these, the two lines showing the most intense labeling of Schwann cells were selected. Because these two lines gave identical labeling of the brain and periphery, one of them, designated "Kosmos," was used for further experiments, and all the other S100-GFP lines were discarded.

A second set of S100-YFP transgenic animals was prepared, using exactly the same construct but with YFP substituted for GFP. Nine of 45 injected embryos brought to term were judged to be potential founders on the basis of Southern blotting and PCR. All nine of these animals had germline integration. Two of the lines were discarded on the basis of dim YFP expression in Schwann cells in muscles. We have analyzed the remaining seven lines and designated them YA, YB, YD, YE, YF, YG, and YH. With the exception of one line (YD), all lines have been bred to homozygosity.

Screening of transgenics. Transgenic founders from the initial series of injections were initially identified by Southern blot analysis of tail DNA with radiolabeled Klenow fragments for GFP sequences and by PCR using primers specific for the EGFP sequence (forward, ATG GTG AGC AAG GGC GAG GAG CT; reverse, TCG TTG GGG TCT TTG CTC AGG GC, yielding a 641 bp product). Founders from a second series of injections of the S100-YFP transgene were identified by the fluorescence detectable in the lens of the eye and in skin (Fig. 1A). The number of transgenes integrated in the four S100-GFP lines, estimated using Southern blotting, was six (Kosmos), four, 12, and three. 
Repetitive in vivo imaging. Vital imaging of 2- to 4-month-old Kosmos mice was conducted using the methods of Lichtman et al. (1987). Briefly, each animal was anesthetized with ketamine and xylazine $(0.10-0.15 \mathrm{ml}$ of a $0.9 \% \mathrm{NaCl}$ solution containing $17.4 \mathrm{mg} / \mathrm{ml}$ ketamine and $2.6 \mathrm{mg} / \mathrm{ml}$ xylazine). A ventral midline incision in the neck exposed the sternomastoid muscle. Acetylcholine receptors (AChRs) were labeled by application of Alexa594- or rhodamine-conjugated $\alpha$-bungarotoxin (Molecular Probes, Eugene, OR), $5 \mu \mathrm{g} / \mathrm{ml}$ in sterile, lactated Ringer's solution applied for $5 \mathrm{~min}$. The animal was intubated endotracheally, and its respiration was driven by a small rodent respirator (model 683; Harvard Apparatus, Holliston, MA). A number 0 coverslip held orthogonal to the optical axis of the microscope was applied to the top surface of the muscle and used to depress slightly the muscle surface to minimize movement and to flatten the field. Images were collected using a Zeiss (Oberkochen, Germany) Axiotech microscope equipped with a $100 \mathrm{~W}$ mercury lamp, $40 \times$ [numerical aperture (NA) 0.75 ] or $63 \times$ (NA 0.9) water immersion objectives, and a MicroMAX $5 \mathrm{MHz}$ cooled CCD camera attached to a Macintosh computer running IP Lab software. Throughout the examination, the intensity of illumination reaching the preparation was reduced 50-90\% using neutral density filters. Filter cubes were inserted into the light path to visualize GFP and rhodamine in turn. An Endow GFP filter set (Chroma Technology, Brattleboro, VT) was used for GFP. Images of the superficial junctions were captured using $2 \times 2$ binning. A similar procedure was followed to image junctions in the soleus muscle. In these cases, the soleus was exposed by incision through the lateral surface of the shank and retraction of the gastrocnemius muscle. Intubation was unnecessary for these experiments. After imaging, the incision was closed with 6-0 silk suture, and the animal was allowed to recover from anesthesia under a heat lamp and then returned to its cage.

Immunostaining of whole mounts and sections. After anesthesia, animals were perfused transcardially with PBS. For examination of the brain, the animal was also perfused with $4 \%$ paraformaldehyde. Brains were dissected and postfixed overnight. For examination of peripheral tissues, these tissues [sternomastoid, extensor digitorum longus (EDL), soleus, diaphragm, and triangularis sterni muscles; sciatic, peroneal, and tibial nerves; intestine, thymus, spleen, and skin] were pinned into Sylgard-coated dishes and fixed in the same fixative for $30 \mathrm{~min}$. For microscopic observation and immunostaining, tissues were observed as whole mounts (procedures are described in Love and Thompson, 1998) or as $\sim 10 \mu \mathrm{m}$ cryostat sections, prepared after cryoprotection (20\% sucrose) and embedding in OCT (TissueTek, Miles, Elkhart, IN).

The procedures for immunostaining have been described (cf. Love and Thompson, 1998). The following primary antibodies were used at the indicated dilutions: rabbit anti-cow S100B (1: 500; Dako, High Wycombe, UK); mouse monoclonal to neurofilament protein and synaptic vesicle protein $(2 \mathrm{H} 3$ and SV2, respectively; 1:500; Developmental Studies Hybridoma Bank, University of Iowa, Iowa City, IA); anti-glial fibrillary acidic protein (GFAP; G3893; 1:100; Sigma, St. Louis, MO); anti-NeuN (MAB377; 1:100; Chemicon, Temecula, CA); Rip antibody (1:50; Developmental Studies Hybridoma Bank); F4/80 rat monoclonal (MCA497R; 1:10-1:50; Serotec, Oxford, UK); FA-11 rat monoclonal (anti-macrosialin-CD68; MCA1957S; 1:10; Serotec); and hamster biotinylated monoclonal anti-CD11c and anti-CD3 $\epsilon$ (553800 and 553239, respectively; 1:100; PharMingen, San Diego, CA). The following secondary antibodies and fluorophore reagents were used at the indicated dilutions: FITC-conjugated goat anti-rabbit (55671; 1:400; Cappel, Cochranville, PA); Alexa594-conjugated goat anti-rat, anti-rabbit, and anti-mouse (A11007, A-11037, and A-11020, respectively; 1:200-500; Molecular Probes); Cy5-conjugated goat anti-rabbit (111-175-144; 1:200; Jackson ImmunoResearch, West Grove, PA); tetramethylrhodamine isothiocyanate (TRITC)-conjugated goat anti-mouse (1070-03; 1:200; Southern Biotechnology); Texas Red donkey anti-rat and anti-rabbit (712-076-153 and 711-075-152, respectively; 1:100; Jackson ImmunoResearch); and Texas Red-streptavidin (SA1003; 1:100; Caltag, South San Francisco, CA).

AChRs were visualized using $\alpha$-bungarotoxin conjugated to rhodamine, Alexa-594, or Alexa-647 (all obtained from Molecular Probes).

Nonvital imaging. Images were collected using a Leica epifluorescence microscope equipped with $40 \times($ NA 1.0) and $63 \times($ NA 1.32) objectives, filter cubes for $4^{\prime}, 6^{\prime}$-diamidino-2-phenylindole (DAPI), GFP, YFP, TRITC, calcium crimson, and Cy5 (Chroma Technology), and an integrating CCD camera (Cool Snap HQ; Roper Scientific). Confocal imaging was performed using a Leica TCS-4. The AChR area within individual junctions was computed from an image of the bungarotoxin label as described previously (Love and Thompson, 1998).

Physiology. Soleus muscles and nerves were dissected and tested as described previously (cf. Lubischer and Thompson, 1999).

Averages in this manuscript are reported as \pm SEM.

\section{Results}

A $9.4 \mathrm{~kb}$ fragment of genomic DNA encompassing the promoter region and first intron of the human $\mathrm{S} 100 \mathrm{~B}$ gene was inserted upstream of the coding region for a fluorescent protein (FP, either EGFP or EYFP) and the SV40 polyadenylation module. The constructs were used to generate 13 lines of S100-GFP and S100YFP mice, eight of which have been retained and analyzed (see Materials and Methods). One line expresses GFP and was designated Kosmos; the remaining seven express YFP and were designated YA, YB, YD, YE, YF, YG, and YH. In the course of screening these animals, we found that those bearing the transgene could be easily distinguished from nontransgenic littermates by examination under a fluorescence dissecting scope (Fig. 1A).

\section{GFP is a reliable marker of Schwann cells in the Kosmos transgenic line}

As expected from the endogenous expression of S100B, myelinating Schwann cells were easily detected by their GFP fluorescence in intramuscular nerves (Fig. $1 B$ ) or in small bundles of axons teased from the sciatic nerve. To examine GFP expression in TSCs at the NMJ, sternomastoid muscles were dissected from the Kosmos line and labeled with an antibody to S100 that marks Schwann cells (Fig. $1 E$ ) and with $\alpha$-bungarotoxin to identify the AChRs concentrated at each junction (Fig. 1C). Almost without exception, every Schwann cell labeled by the S100 antibody was also labeled with GFP (Fig. 1, compare D,E). Of 197 junctions examined in sternomastoid muscles from four animals, there were only two junctions (one cell in each) in which there was any doubt of colabeling. The brightly fluorescent ovals revealed by anti-S100 and GFP were shown to be cell bodies by using a nuclear marker (DAPI; data not shown). Processes extending from these cell bodies covered the nerve terminal (identified by labeling with antibodies to neurofilament and synaptic vesicle proteins; data not shown). These processes could be visualized as well by their GFP fluorescence as by their S100 labeling. In addition to TSCs, GFP labeled the myelinating Schwann cells (Fig. 1D, dou- 
ble arrowhead) wrapping the motor axon (data not shown) that entered each junction. Identical GFP labeling was obtained regardless of whether the sternomastoid, soleus, EDL, diaphragm or triangularis sterni muscles were examined. We conclude that, in the Kosmos line, GFP is a reliable marker of Schwann cells. Such GFP labeling was present at the time of birth (data not shown).

\section{Junctions with fluorescent Schwann cells have normal morphology and physiology}

Transgenic expression of GFP in mammals is generally nontoxic (cf. Feng et al., 2000), but other studies have identified detrimental effects (cf. Huang et al., 2000). Although mice of the Kosmos line are seemingly normal in appearance, behavior and fertility, even when homozygous for the transgene, we were particularly interested in whether there were changes in the physiology and morphology of their NMJs.

To examine the morphology of transgenic NMJs, muscles were dissected from three transgenic Kosmos animals and three nontransgenic littermates at 2-3 months of age, fixed, and AChR and Schwann cells were labeled with different fluorophores. There were differences among the muscles (sternomastoid, soleus, and EDL) in the total area of their AChR-rich synaptic sites $\left(490 \pm 170 \mu \mathrm{m}^{2}\right.$ in EDL to $695 \pm 288 \mu \mathrm{m}^{2}$ in sternomastoid $)$ and the number of Schwann cells per site $(2.3 \pm 0.8$ in EDL to $3.3 \pm$ 0.5 in sternomastoid). However, there were no significant differences in these parameters between transgenic and nontransgenic animals. At both transgenic and nontransgenic NMJs, TSCs precisely covered the nerve terminal.

To examine neuromuscular transmission and the organization of motor units, soleus muscles were dissected with their nerves from transgenic $(n=5)$ and nontransgenic $(n=2)$ animals, pinned into a dish, and superfused with oxygenated Ringer's solution. Each muscle was connected to a tension transducer, and its nerve was stimulated with a suction electrode. There were no obvious differences in motor unit number, peak twitch tension, tetanic tension generated in response to stimulation of the nerve at 50 or $100 \mathrm{~Hz}$, or tension produced by direct stimulation of the muscle (data not shown).

By these criteria, there are no detectable differences in the innervation of muscles of Kosmos despite the expression of soluble GFP in their Schwann cells.

Vital imaging of Kosmos neuromuscular junctions shows the stability of the glial components of this synapse

To assess the feasibility of vitally imaging Schwann cells at living NMJs, we exposed the sternomastoid muscle in anesthetized mice of the Kosmos line, labeled the AChR with nonblocking doses of rhodamine-conjugated bungarotoxin, and used an epifluorescence microscope to visualize receptor areas and the brightly labeled Schwann cells and their processes. We collected an initial set of images of 30 junctions that could be viewed en face in five animals at 2 months of age. Thirty days later we attempted to reimage these same junctions, identifying them on the basis of the unique, pretzel-like shape of their AChR (Fig. 2). We were successful in 25 cases; the remaining five had become situated on the sides of their muscle fibers. Most of the reimaged junctions (18) showed no major change in the position or number of Schwann cell bodies. Five of the junctions had added a Schwann cell body, and two had apparently lost a Schwann cell body. The synaptic AChRs were unchanged in all but three cases where there was a minor $(<5 \%)$ loss of receptor area (Fig. 2, compare $A, D)$. The lost receptor areas were located where the motor axon en-
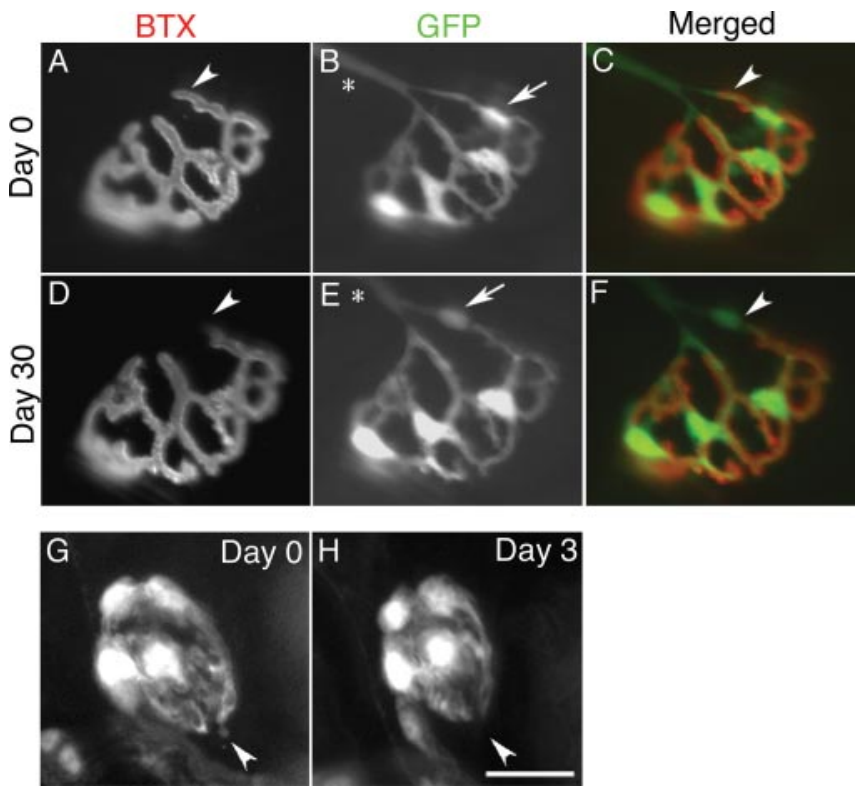

Figure 2. GFP enables vital imaging of synaptic glia at the NMJ and provides evidence of their stability. $A-F$, Images of the same NMJ in the sternomastoid muscle of a living Kosmos transgenic mouse obtained 30 d apart. $A-C$, Junction at first view. $D-F$, Same junction reimaged 30 d later. $A, D, A C h R s$ labeled with a nonblocking concentration of rhodamine-bungarotoxin (BTX). $B, E$, Schwann cells viewed by their GFP fluorescence. $C, F$, Merged images with receptors pseudocolored red and Schwann cells green. Schwann cells wrapping the nerve entering the junction can be identified ( $B, E$, asterisks). This junction grew somewhat in size between viewings, but the geometry of its receptors and TSCs remained remarkably constant. The Schwann cells did not change the location of their cell bodies, except for the topmost Schwann cell $(B, E$, arrow), which moved to occupy a position further back along the top preterminal branch entering the junction. A small portion of the receptor area near the site of nerve entry was lost between the two views ( $A, C, D, F$, arrowheads). $G, H$, Images of a single NMJ in the soleus of the Kosmos line. Despite their overall stability, TSCs extend and retract short processes. Processes present on the first day $(G$, arrowhead) that are extended beyond the AChRs (data not shown) were absent when a second image was collected $3 \mathrm{~d}$ later $(H)$. Scale bar: $A--F, 30 \mu \mathrm{m}$; $G, H, 20 \mu \mathrm{m}$.

tered the junction. Such losses of receptor areas have been previously observed by vital imaging (Balice-Gordon and Lichtman, 1993) and were suggested to result from loss of a functioning synaptic contact at these sites, perhaps because of encroachment of myelinating glia into previously synaptic areas. These experiments show the feasibility of performing repeated, vital imaging of Schwann cells at neuromuscular synapses. Moreover, they add to previous demonstrations that adult, mammalian NMJs have stable receptor areas and nerve terminals (Lichtman et al., 1987) by showing that this stability also applies to the associated glial cells.

\section{Vital imaging shows terminal Schwann cells extend and retract short processes}

During repeated, vital imaging of junctions in the sternomastoid and soleus muscles, we encountered TSCs that had extended short processes (Fig. $2 G$ ) (average length $=1.1 \pm 0.1 \mu \mathrm{m}, 66$ processes) beyond the edge of the AChR (data not shown). These processes were present at approximately half of the junctions (42 of 90 in 32 sternomastoid muscles; 56 of 98 in 16 soleus muscles) and were much shorter than the numerous, longer extensions found after denervation (Son and Thompson, 1995a). To determine whether these short extensions might have been induced by the surgery or imaging, we examined sternomastoid and soleus muscles taken acutely from Kosmos or from nontransgenic animals, and we identified Schwann cells in the latter case by labeling 
Table 1. FP expression among the S100-FP lines

\begin{tabular}{|c|c|c|c|c|}
\hline \multirow{2}{*}{$\begin{array}{l}\text { S100-FP } \\
\text { line }\end{array}$} & \multicolumn{4}{|l|}{ FP expression } \\
\hline & Schwann cells & Motor axons & Muscle macrophages & CNS \\
\hline Kosmos & All, in all muscles examined & None & Very few & Astrocytes; Bergmann glia \\
\hline YA & $\begin{array}{l}\text { Subsets, }+ \text { in so, ts, di; } \\
+++ \text { in st, EDL; weak } \\
\text { expression in so }\end{array}$ & $\begin{array}{l}\text { Subsets, }+ \text { in so, di; }++ \\
\text { in st, EDL; }+++ \text { in ts }\end{array}$ & $\begin{array}{c}\text { Few-many so, EDL } \\
\quad<\text { st }<\text { ts, di }\end{array}$ & $\begin{array}{l}\text { Microglia with few or weak } \\
\text { astrocytes; Subset of Berg- } \\
\text { mann glia }\end{array}$ \\
\hline YB & $\begin{array}{l}\text { Weak expression in subsets. } \\
+ \text { in so, di; + + in st, } \\
\text { EDL, tri }\end{array}$ & $\begin{array}{l}\text { Subsets, none in di, so; } \\
\qquad+++ \text { in st, EDL, ts }\end{array}$ & Few & Dim labeling \\
\hline YD & $\begin{array}{l}\text { Subsets, }++ \text { in st, di, ts, } \\
\text { so; }+++ \text { in EDL; weak } \\
\text { expression in so and di }\end{array}$ & $\begin{array}{l}\text { Subsets, }+ \text { in so, di; ++ } \\
\text { in st, EDL, ts }\end{array}$ & $\begin{array}{l}\text { Few-many } \\
\text { so }<\text { st, EDL }<\text { ts, di }\end{array}$ & $\begin{array}{l}\text { Bright microglia, dim astrocytes; } \\
\text { Bergmann glia }\end{array}$ \\
\hline YE & $\begin{array}{l}\text { Subsets, }++ \text { in ts, di, st; } \\
+++ \text { in so, EDL; weak } \\
\text { expression in so and di }\end{array}$ & $\begin{array}{l}\text { Subsets, }++ \text { in st, EDL, di; } \\
+++ \text { in ts }\end{array}$ & $\begin{array}{l}\text { Some-many } \\
\text { st, so, EDL }<\mathrm{ts} \text {, di }\end{array}$ & Not examined \\
\hline YF & All, in all muscles examined & $\begin{array}{l}\text { Subsets, None in ts, so, di, } \\
\text { EDL; + + in st }\end{array}$ & $\begin{array}{l}\text { Few-many } \\
\text { st, so, EDL }<\text { ts }<\text { di }\end{array}$ & $\begin{array}{l}\text { Bright microglia, dim astrocytes; } \\
\text { Bergmann glia }\end{array}$ \\
\hline YG & All, in all muscles examined & $\begin{array}{l}\text { Subsets, None in di, so; + } \\
\text { in st, ts, EDL }\end{array}$ & Few & $\begin{array}{l}\text { Bright microglia, dim astrocytes; } \\
\text { Bergmann glia }\end{array}$ \\
\hline $\mathrm{YH}$ & $\begin{array}{l}\text { Weak expression in subsets. } \\
\text { none in so, di; + in st, } \\
\text { EDL, ts }\end{array}$ & $\begin{array}{r}\text { Subsets, }++ \text { in di, so; } \\
+++ \text { in st, EDL, ts }\end{array}$ & $\begin{array}{l}\text { Some-many } \\
\text { st, so, EDL }<\mathrm{ts} \text {, di }\end{array}$ & $\begin{array}{l}\text { Bright microglia, dim astrocytes; } \\
\text { Bergmann glia }\end{array}$ \\
\hline
\end{tabular}

Sizes of subsets are indicated as +++ for most, ++ for some, and + for few of cells present. For each line, two to eight muscles and one to four brains were examined. st, Sternomastoid; so, soleus; EDL, extensor digiforum longus; ts, triangularis sterni; di, diaphragm.

with anti-S100. Short Schwann cell processes were again found at approximately half of the junctions (21 of 43 junctions in two transgenic animals; 13 of 30 junctions in two nontransgenic animals). We conclude that these short processes are normal features of terminal Schwann cells at mouse NMJs. Repeated imaging of individual junctions suggests that these short Schwann cell processes are dynamic. Some short Schwann cell processes present at the first imaging were absent when a second image was collected within $3 \mathrm{~d}$ of the first image (Fig. $2 \mathrm{H}$ ), and some synaptic sites had short processes at a second viewing that were absent at the first viewing. These observations suggest that Schwann cells extend and retract short processes in the environment around the synaptic site.

\section{In some lines, subsets of Schwann cells are labeled and nonrandomly distributed to NMJs}

Other transgenic lines we generated had labeling in some unexpected cell types (Table 1). We first consider the labeling encountered within the peripheral nerves and muscles, then other organs, and finally the CNS. Mice of each of the YFP lines were found to have some labeled motor axons and motor nerve terminals, either with or without labeling of Schwann cells (Fig. 3A,B). In these cases, the labeling of motor neurons could be confirmed in sections of the spinal cord (data not shown). Because spinal motor neurons are not labeled with antibodies to S100B, this YFP-labeling is an artifact of transgenesis in these lines. Although the majority of motor neurons appeared to be labeled in some lines, in other lines only small subsets of motor neurons were labeled, although the size of the subset varied (Table 1). In addition, muscles of mice from some of the lines had many labeled motor neurons, whereas other muscles in the same animals had none. The labeling of motor axons appeared late in postnatal development [postnatal day 7 (P7)], although expression in glial cells could be detected at birth (see below).

Besides the unexpected labeling of motoneurons, subsets of Schwann cells were labeled in some of the lines (Table 1, Fig. 3B). We examined more fully the labeling of Schwann cell subsets in sternomastoid and triangularis sterni muscles of the YA and YH lines. Surprisingly, the labeled cells appeared to be distributed nonrandomly: at most junctions, the TSCs were either all YFP+ or all YFP- (Fig. 3A,B). Junctions of each type were intermixed in the muscle. To assess this labeling pattern quantitatively, we dissected sternomastoid muscles from three different YA animals and a single $\mathrm{YH}$ animal, and labeled them with antibodies to S100B to identify all the TSCs present at individual junctions. For each superficial junction (i.e., those having access to the antibody), we counted the number of TSCs that were YFP+ and YFP-. For example, in one of these muscles (from animal YA36-1), 38 superficial junctions had a total of 139 TSCs labeled with anti-S100B, yielding an average of 3.7 TSCs per junction. Of these TSCs, $81 \%$ (112 of 139) were YFP +. These YFP + cells were distributed so that at $68 \%$ of junctions (26 of 38) all TSCs were YFP + , at $16 \%$ (6 of 38) all TSCs were YFP-, and at 16\% (6 of 38), there was a mixture of YFP + and YFP- TSCs (Fig. 4A). Thus, $84 \%$ ( 32 of 38 ) of the junctions had homogenous labeling (either all TSCs YFP + or all YFP-). If labeled and unlabeled TSCs were distributed randomly among junctions with each of these TSCs having a probability of being YFP + of 0.81 and 3.7 TSCs situated on each junction, then it would be expected that $45.9 \%$ of the junctions would have all their TSCs YFP $+\left(0.81^{3.7}\right), 0.2 \%$ of them would have no YFP+ Schwann cells $\left(0.19^{3.7}\right)$, and $53.9 \%$ would have mixtures of YFP+ and YFP - cells (Fig. 4A). Thus, the percentage of junctions expected to be homogeneous would be $46.1 \%$ rather than the observed $84 \%$.

This deviation from the expectation of a random distribution was found for an additional two muscles, each from a different YA animal and each having a different fraction of their TSC population labeled with YFP (Fig. $4 A$, legend). In these two additional muscles, the observed percentages of homogenous junctions, 89 and $100 \%$, were again much larger than those predicted by chance, 28 and 32\%, respectively. Thus, despite animal-toanimal variation in extent of labeling of the TSC population, the tendency for nonrandom sorting of YFP+ and YFP - cells was consistent. A similar tendency for homogeneity in the TSCs at 

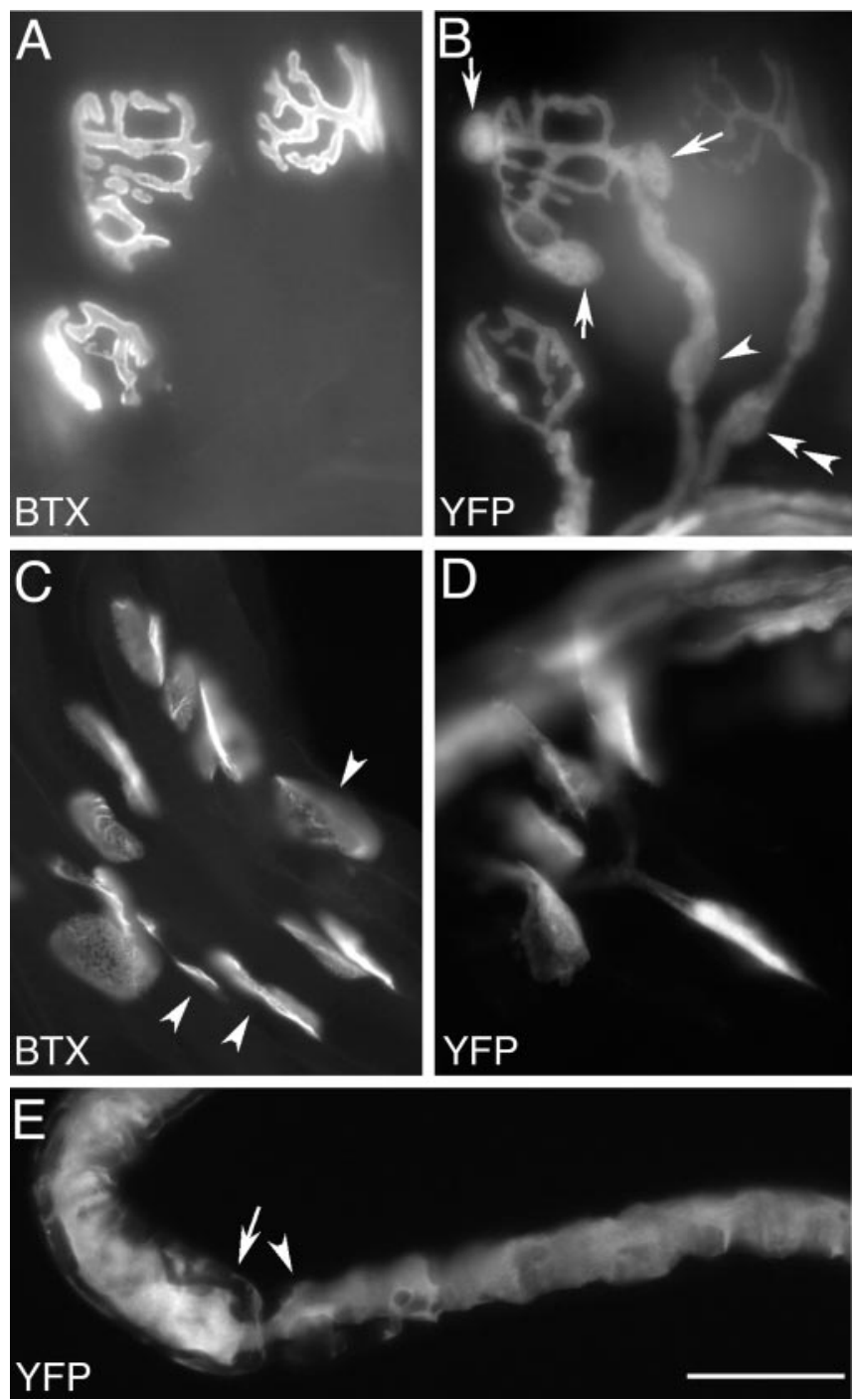

Figure 3. Variegated FP labeling in the YA line. $A, B$, YFP labels motor axons, nerve terminals, and a subset of TSCs and myelinating Schwann cells in an adult triangularis sterni muscle. AChR labeled with Alexa-594 - bungarotoxin (BTX, A); YFP label (B). Cell bodies of YFP + TSCS are present at the central junction in this photomicrograph $(B$, arrows), whereas the other two junctions have no YFP + TSCS, but do have YFP-labeled motor axons and terminals. YFP+ Schwann cells are present along some axons leading to junctions that have (arrowhead) or do not have (double arrowhead) YFP-expressing TSCS. C, D, YFP labels a subset of TSCs in the sternomastoid of a newborn YA animal. AChR labeled with Alexa-594-bungarotoxin (BTX, C); YFP fluorescence (YFP, D). YFP-expressing TSCs are seen at some junctions but not at others ( $C$, arrowheads). No YFP is seen in axons at this stage of development. $E$, Single axon teased from the nerve to a YA sternomastoid muscle is strongly YFP +. Despite its labeling, this axon is clearly associated with both YFP + and YFP - myelinating Schwann cells. The myelinating Schwann cell to the left (arrow) is weakly YFP +, whereas the Schwann cell (arrowhead) to the right of the node is YFP - Scale bar: $A-D, 32 \mu \mathrm{m} ; E, 25 \mu \mathrm{m}$.

individual junctions was also observed in one $\mathrm{YH}$ sternomastoid (observed 75\%, predicted 34\%). The differences in observed versus predicted homogeneity in YA animals would be expected by chance in $<5 \%$ of the cases (paired $t$ test; $n=3$ YA muscles), making them statistically significant. It is interesting to note that the YFP status ( + or - ) of TSCs was apparently mirrored by the YFP status of the myelinating Schwann cell forming the last internode before the junction. A total of 125 junctions and their axons were analyzed in this manner in two YA sternomastoid muscles. For 50 of these junctions, YFP was present in both the
Schwann cell forming the last internode and the TSCs; for 72 of them, YFP was present in neither; only three of them had no label in the Schwann cell on the last internode but some YFP+ TSCs.

One possible explanation for this nonrandom distribution of YFP + and YFP - cells is that YFP is expressed in response to local influences exerted by the particular motor axon or muscle fiber with which TSCs associate. Bundles of axons teased from the sciatic or tibial nerves of YA animals showed that myelinating Schwann cells also had this variegation: some were YFP+, and some were YFP - (data not shown). Thus, the variegation occurs some distance from the peripheral targets of these axons, making it unlikely that a muscle-derived signal is controlling YFP expression. Moreover, it was possible in some cases to observe single axons teased from peripheral nerves over several internodes. In these cases, axons were observed that had one or more internodes wrapped by YFP + Schwann cells while an adjacent internode was wrapped by a YFP - Schwann cell (Fig. 3E). Because the YFP expression along single axons can be nonuniform, it appears unlikely that axons direct YFP expression in Schwann cells.

YFP expression in Schwann cells could be stable, or it could change over time. We addressed this issue in two ways. First, we vitally imaged the TSCs at 39 NMJs in the sternomastoid muscles of four YA 3-month-old mice as described above. Of these 39 NMJs, 17 had YFP+ TSCs, and most of these also had YFP+ axons, whereas the remaining 22 junctions had only axonal labeling. Thirty days later we reimaged these same NMJs, and we found that all of the junctions retained their original labeling pattern (Fig. 5), with one exception. In this single case, a junction that had YFP + TSCs on the initial viewing had added an additional YFP + TSC by the second viewing. Thus, YFP expression in TSCs appears stable, at least over an interval of $30 \mathrm{~d}$ in adult animals. As a second approach, we attempted to determine whether there is an obvious switch in YFP expression during development. We observed that YFP + and YFP - TSCs were present at sternomastoid NMJs at the time of birth (Fig. 3C,D). Therefore, the variegation seen in the adult does not emerge from uniformity present at birth. If Schwann cells do switch their expression pattern postnatally, this change must occur coordinately in groups of cells, otherwise mixtures of cell types would be more common.

Homogeneous YFP expression in the TSC population at individual NMJs could arise during development by sorting of SCs during the process of neonatal synapse elimination, because each junction loses synaptic inputs to become innervated by a single motor axon (Brown et al., 1976). We examined three sternomastoid muscles dissected from three YA animals on P6, using the same methods outlined above for adult muscles. Fewer TSCs were present at P6 junctions (an average of three, compared with approximately four in the adult), a finding consistent with reports that Schwann cells are added to junctions during postnatal development (Love and Thompson, 1998). The percentage of S100+ TSCs that were YFP + in these muscles was 66,60 , and $58 \%$. Based on a random assortment of Schwann cells according to their YFP phenotype, the expected frequencies of homogenous junctions were 33,28 , and $27 \%$ (Fig. $4 B$ ), significantly lower than the observed 90, 87, and $88 \%(p<0.001 ; n=3$; paired $t$ test $)$. Thus, TSCs at individual junctions tend to be of the same YFP status at P6, although half the junctions receive input from more than one motor axon at this time (Balice-Gordon and Lichtman, 1993). This homogeneity in Schwann cells and its possible interpretation is discussed below. 

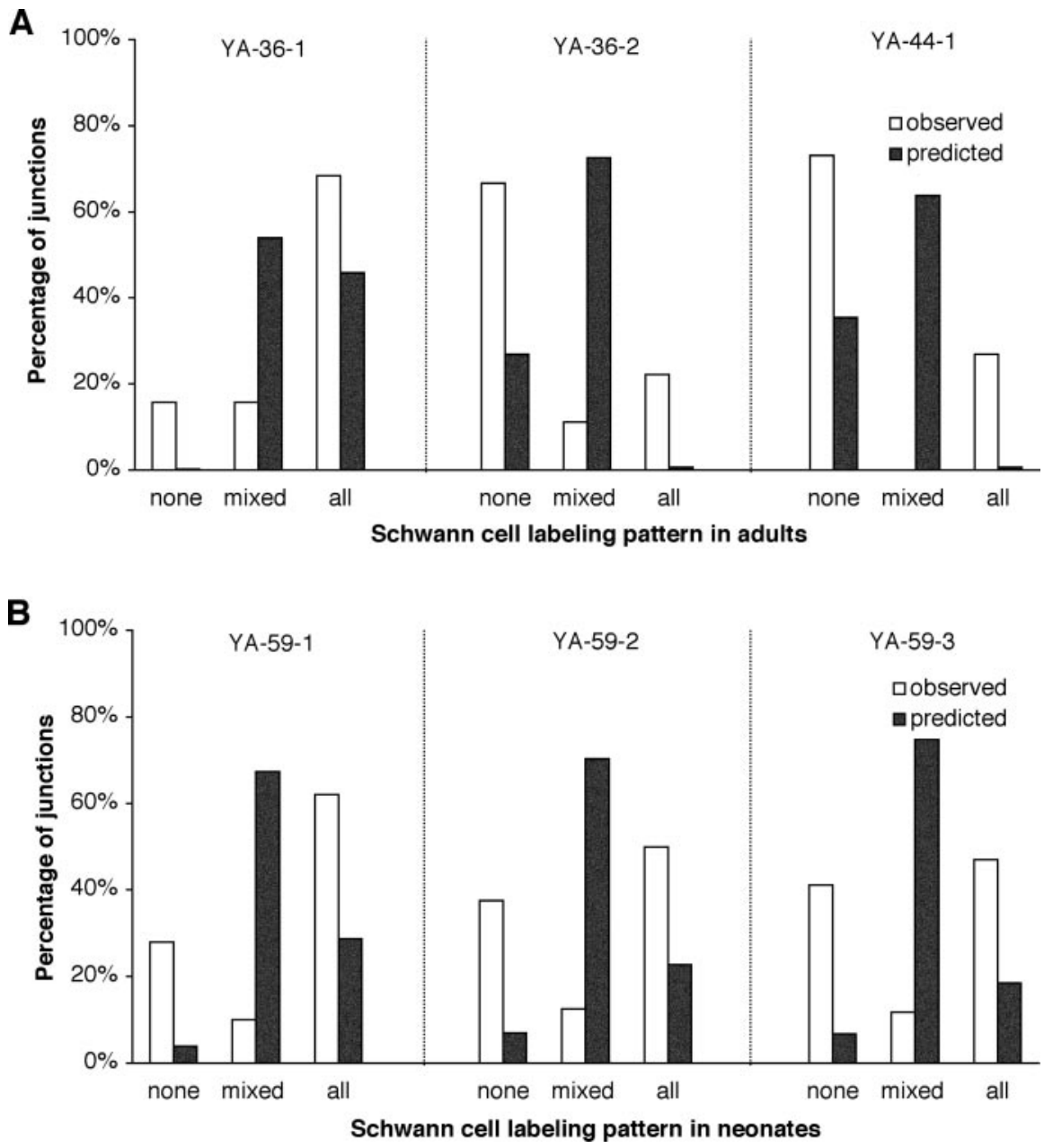

Figure 4. The YFP + subset of TSCs is nonrandomly distributed at adult and neonatal NMJs. A, TSC labeling at NMJs in sternomastoid muscles from three adult YA animals. B, TSC labeling at NMJs in sternomastoid muscles of three 6-d-old YA animals. The YFP status (labeled or unlabeled) of each anti-S100-positive TSC was determined at 17-50 NMJs in each muscle. The pattern at each junction was classified as "none" if none of the TSCs were YFP +, "mixed" if both YFP + and YFP - TSCs were present, and "all" if all of the TSCS were YFP +. Open bars indicate observed frequencies of junctions of each type. Closed bars indicate the predicted frequency of junctions of each type based on a random sorting of TSCs whose individual probability of being labeling is given by the overall frequency of YFP + cells in that muscle. The number of junctions examined, the average number of TSCS per junction, and the overall frequency of YFP + TSCS were as follows: A, YA-36-1: 38, 3.7, 81\%; YA-36-2: 18, 4.0, 28\%; YA-44-1: 26, 3.6; 25\%; B, YA-59-1: 50, 3.0, 66\%; YA-59-2: 40, 2.9, 60\%; and YA-59-3: 17, 3.1, 58\%.

Resident macrophages in muscles and peripheral nerves express YFP and respond to injury in several lines

In addition to expression in Schwann cells and axons, the YA, YD, YE, YF, and YH lines had prominent YFP labeling within a population of cells scattered among muscle fibers, peripheral nerve fibers, and their connective tissues (Fig. 6A,B). These cells had short processes that were usually oriented along the axons or muscle fibers. These cells were not labeled by anti-S100 antibody (Fig. 6C,D), and thus represent another example of apparently aberrant expression of the transgene. Such labeled cells were particularly prominent in the triangularis sterni and diaphragm. Because these YFP + cells resemble "resident" macrophages known to be present within tissues (cf. Gordon et al., 1992), we immunostained sections of muscle and nerve with antibodies to the murine macrophage markers F4/80 and FA-11 (Gordon et al., 1992) (supplemental Fig. 1, available at www.jneurosci.org as supplemental material). In sections of the EDL muscles and plantar nerves of YH mice, $>80 \%$ of the YFP + cells were labeled by these antibodies (data not shown). However, some cells positive for the macrophage markers were not $\mathrm{YFP}+$. We conclude that the YFP label in some of our lines serves as a marker for a subset of resident macrophages in muscles and nerves, as it does for lymphoid tissues (see below). All the FP lines we generated have at least an occasional, rare FP+ cell located outside the NMJ that is obviously not a Schwann cell, but the frequency of such labeled cells is dramatically higher in the $\mathrm{YE}$ and $\mathrm{YH}$ lines and moderately higher in the YA, YD, and YF lines. Thus, there is considerable line-to-line variability in the extent of labeling of macrophages, suggesting that macrophage subsets are labeled in the different lines.

Because macrophages are known to accumulate at sites of tissue damage (cf. Monaco et al., 1992), we tested whether damage to superficial muscle fibers or to the sciatic nerve would lead to accumulation of YFP + macrophages. One day after nerve crush, the density of YFP + cells at the crush site was at least five times as high as that at sites approximately a millimeter away (data not shown). Six days after resection of the sciatic nerve, YFP + cells had filled the nerve distal to the site of resection (data not shown). Such YFP+ cells were still present $14 \mathrm{~d}$ later. Most of these cells appeared to be filled with phagocytic vacuoles (supplemental Fig. 1C,D, available at www.jneurosci.org as supplemental material). Two days after injury to muscle fibers (cutting a few superficial fibers with iridectomy scissors), YFP + cells accumulated at the injury site and along individual, degenerating fibers on each side of the injury site. Confocal imaging showed rounded, $\mathrm{YFP}+$ cells were present on the surface and inside these fibers (Fig. 6E,F). Thus, the YA, YE, and YH lines could be used for the vital imaging of macrophages at sites of tissue injury.

Labeling of the lens of the eye, adipocytes, and blood-derived Langerhans and dendritic cells mimics endogenous expression of $\mathrm{S} 100 \mathrm{~B}$

All of the S100-FP animals we generated had FP labeling in conspicuous, non-neural structures of the periphery that were easily detected using a fluorescence dissecting scope. For example, all transgenic animals had fluorescent eyes and skin (Fig. 1A). By dissection, the lens itself was found to be brightly fluorescent (data not shown). Microscopic examination of the skin showed the presence of evenly spaced cells with extensive, dendritic-like processes (Fig. 7A). These cells, on the basis of their morphology and location (cf. Romani et al., 2003), are Langerhans cells, antigen-presenting cells of skin. Dissection of the mice under a fluorescence dissecting microscope revealed prominent labeling in bone marrow and cartilage (data not shown), adipocytes (data not shown), the thymus and spleen (Fig. $7 B, C$ ), mesenteric lymph nodes, and Peyer's patches under the serosal surface of the intestines (Fig. 7D, inset). In some of the lines with particularly 


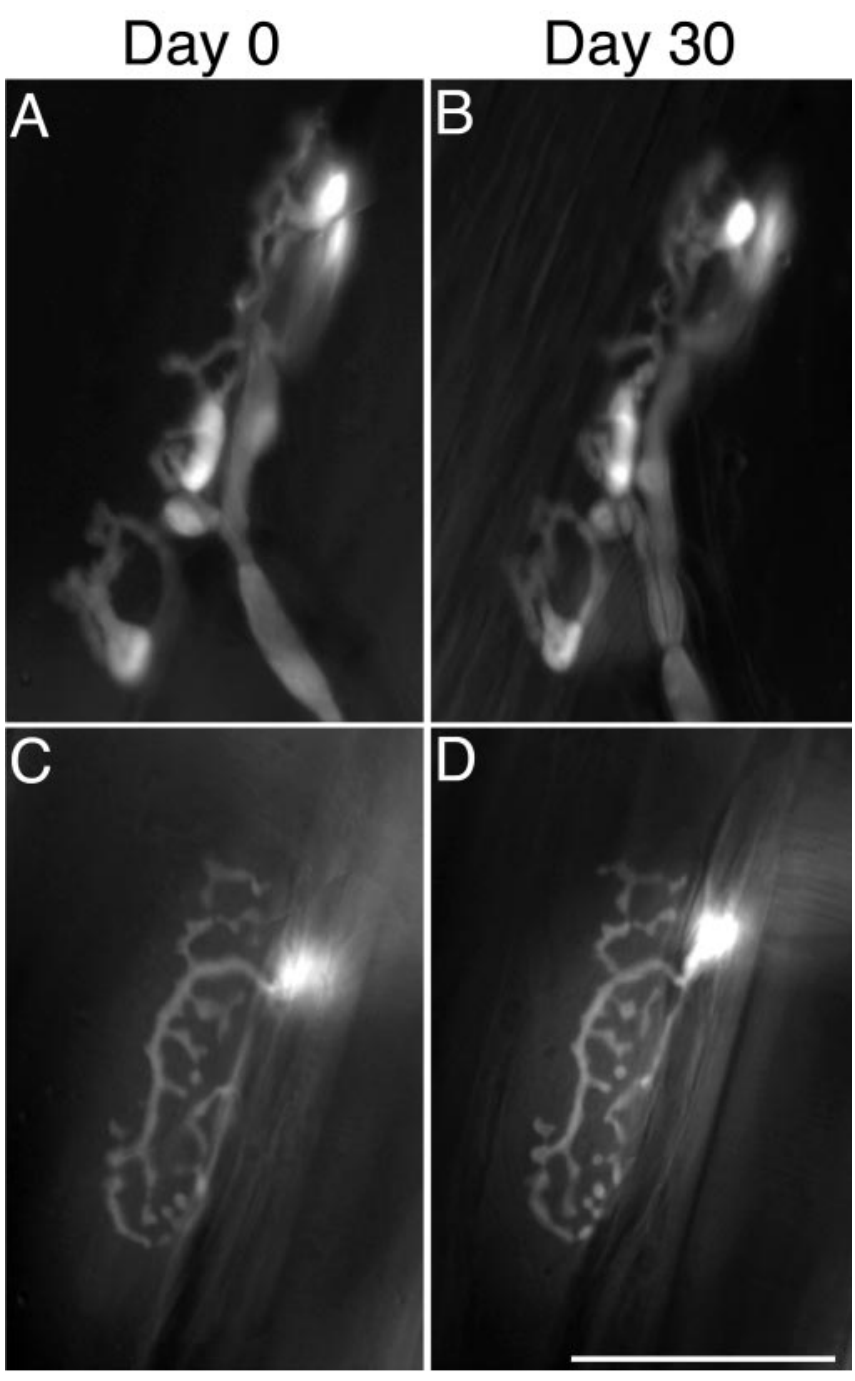

Figure 5. Vital images of NMJs in the YA line show that YFP + and YFP - TSCs retain their phenotype in adults. Images of YFP fluorescence obtained $30 \mathrm{~d}$ apart from two junctions in sternomastoid muscles. Images of AChR are not shown. A, B, NMJ in which TSCs express YFP. C, $D$, NMJ in which TSCs are YFP - but the motor nerve terminal is YFP +. Scale bar, $50 \mu \mathrm{m}$.

bright fluorescence, cells could also be seen in other internal organs (e.g., lungs, heart, liver). Fluorescent cells were also encountered in blood smears and were occasionally seen moving through capillaries during the vital imaging of NMJs.

Examination of cryostat sections of thymus, spleen, and intestine from a mouse of the YF line showed that some dendritic cells (marked by anti-CD11c) (supplemental Fig. 2, available at www.jneurosci.org as supplemental material) and some macrophages (marked by antibody F4/80; data not shown) expressed YFP. YFP+ dendritic cells were encountered in the anticipated locations: in the cortex and medulla of the thymus (data not shown) and as interdigitating cells in T-cell-containing cryptopatches, B- and T-cell-containing Peyer's patches, and the lamina propria of the small and large intestines (data not shown). B- and T-cells were YFP - in all locations (data not shown). Dendritic cells have been previously reported to express S100B (Cocchia et al., 1981, 1983; Michetti et al., 1983, 1985). In our material, however, many YFP + dendritic cells were not labeled by a polyclonal antibody to S100B, suggesting that the relationship between expression of the endogenous gene and the transgene is an artifact of transgenesis.
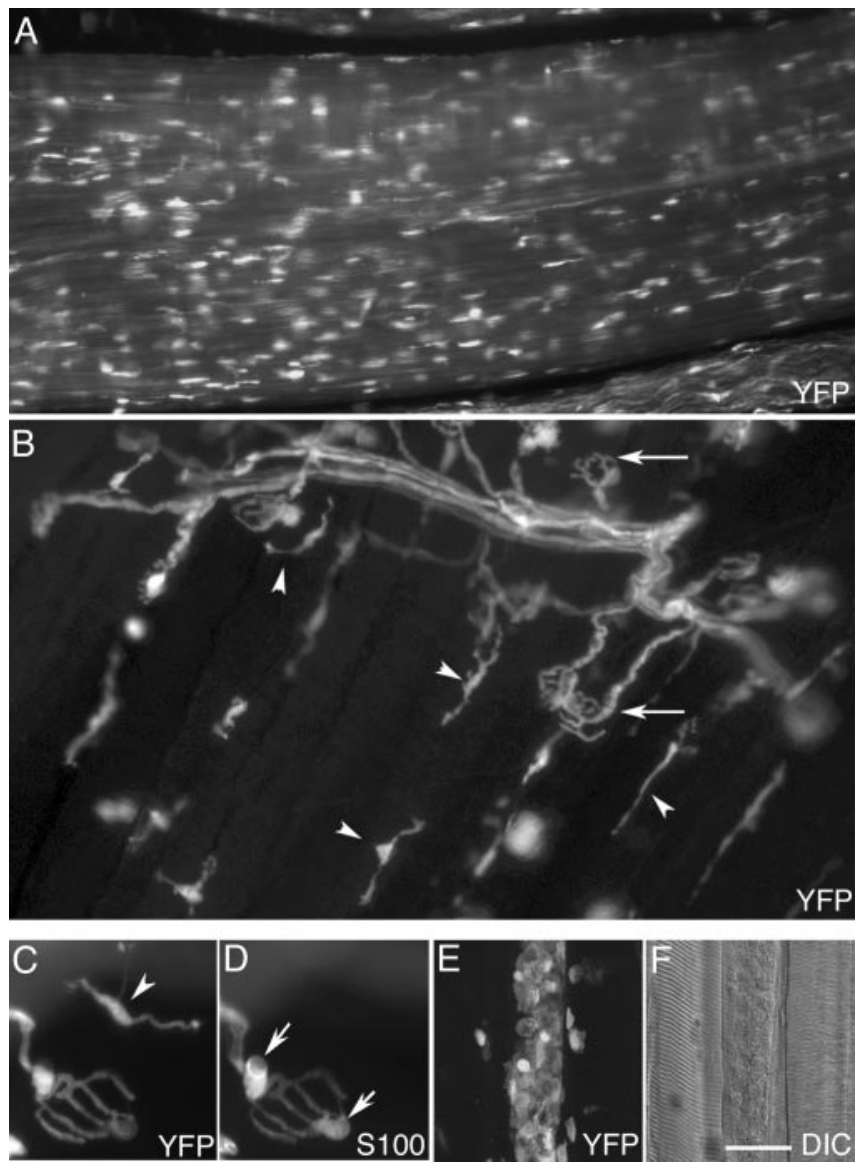

Figure 6. Some transgenic lines have prominent labeling of resident macrophages within nerve and muscle, and these cells accumulate at sites of injury. A, YFP fluorescence from the plantar branch of the sciatic nerve from an animal of the YH line. YFP + cells are oriented mostly along the axis of axons that run horizontally in this image. $B$, YFP fluorescence from the triangularis sterni muscle of a YE animal. Near the top of the panel, YFP + axons within the intramuscular nerve form NMJs (arrows). In addition, there are YFP+ macrophages (arrowheads) located along the fibers throughout the muscle that have no obvious relation to NMJs. The processes of these cells are commonly oriented along muscle fibers, i.e., at $\sim 45^{\circ}$ in this image. $C, D$, Higher-magnification image of a junction from a muscle like that in $B$, showing YFP labeling of the motor axon and terminal $(C)$ and labeling of the Schwann cells with an anti-S100 antibody (D). YFP is present in two TSCs present at the junction that are labeled by anti-S100 as well ( $D$, arrows). YFP is also present in a nearby cell with several processes (C, arrowhead) that is negative for $S 100(D)$. E, F, In a sternomastoid muscle of a YE animal, YFP + cells $(E)$ accumulate within and around a muscle fiber $2 \mathrm{~d}$ after that fiber was injured with iridectomy scissors. The DIC image $(F)$ shows that the sarcomeric organization clearly evident in adjoining fibers is absent from the damaged fiber. Scale bar: $A, E, F, 50 \mu \mathrm{m} ; B, 35 \mu \mathrm{m} ; C, D, 25 \mu \mathrm{m}$.

\section{Fluorescent proteins are expressed in astrocytes in the CNS}

Because $S 100$ has been commonly used as an astrocytic marker in the CNS (cf. Ghandour et al., 1981), our expectation was that FPs would be expressed in these cells in our transgenics. This expectation was met to varying extents in the different lines. In the more extensively examined Kosmos line, GFP + cells that colabeled with anti-GFAP, an astrocytic marker (supplemental Fig. $4 A-C$, available at www.jneurosci.org as supplemental material), were present throughout the CNS. However, not all astrocytes (GFAP-positive cells) expressed GFP (data not shown). In the brains of Kosmos mice, no GFP-expressing cells were labeled by antibodies to the neuron-specific protein NeuN (Mullen et al., 1992). In hippocampus of these mice, GFP + cell bodies were absent in the pyramidal and granule cell layers (supplemental Fig. $3 A$, available at www.jneurosci.org as supplemental material), but GFP-labeled processes outlined the cell bodies of many of the 

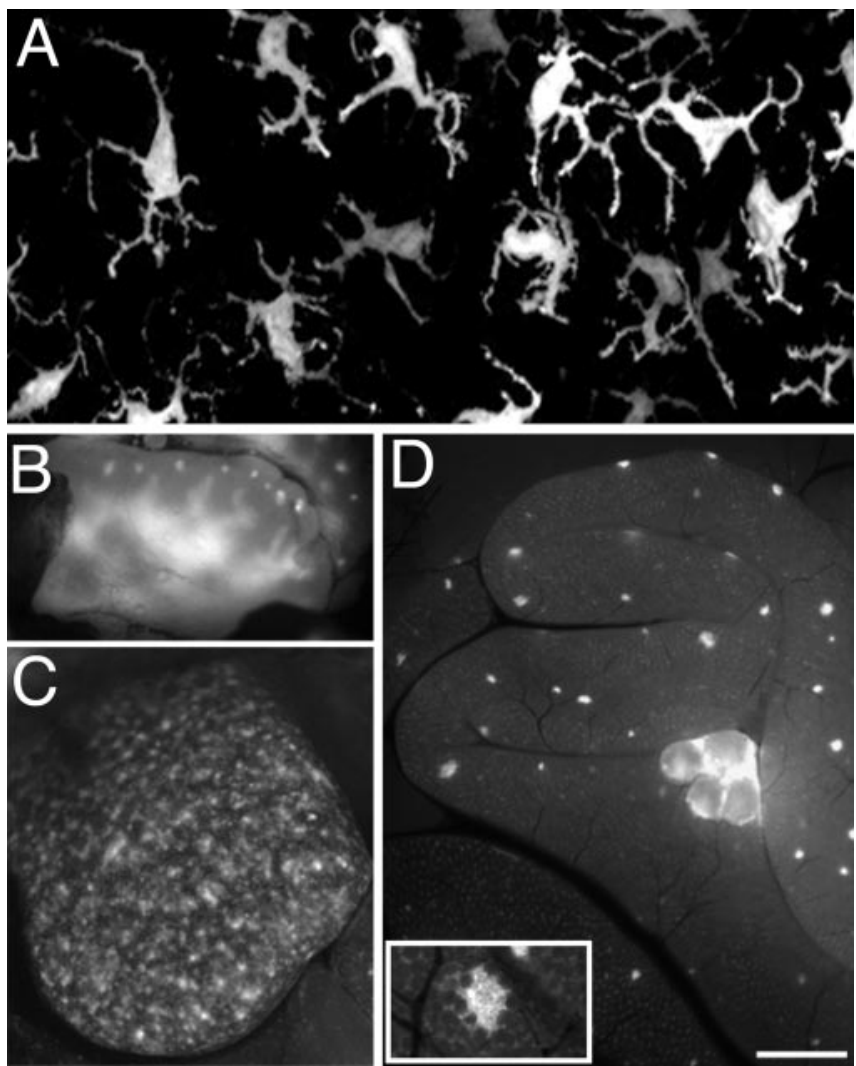

Figure 7. YFP labels cells in the skin, thymus, spleen, and intestine. $A$, Confocal image of fluorescent Langerhans cells in the skin of the ear of a YE animal. Processes of these cells are oriented toward the surface of the skin. $B$, Thymus of a $\mathrm{YH}$ animal. Fluorescent cells are present in the medulla and in the cortex of each lobule. C, Spleen of a YH animal. Fluorescent cells are present in the lymphoid follicles of the white pulp. D, The intestine of a YH animal has bright fluorescence in submucosal Peyer's patches visible just under the outer serosal layer (the smaller spots) and in mesenteric lymph nodes (the larger structures). Inset in D shows a highermagnification image of a Peyer's patch in the submucosal layer of the small intestine of a YF animal. Scale bar: $A, 18 \mu \mathrm{m} ; B, C, 1.5 \mathrm{~mm} ; D, 2 \mathrm{~mm}$; insert, $0.5 \mathrm{~mm}$.

neurons. Similar labeling was seen in the spinal cord and cerebral cortex (data not shown). In the cerebellum, GFP was expressed in astrocytic-like cells in the granule and Purkinje cell layers, but the most prominent labeling was in Bergmann glia, with the molecular layer being intensely fluorescent (supplemental Fig. 3B, available at www.jneurosci.org as supplemental material). No GFP + cells were colabeled with the Rip antibody to oligodendrocytes (Friedman et al., 1989), indicating that these glia do not express the transgene (data not shown). In the olfactory bulb, GFP was brightest in the olfactory nerve layer and sparse in areas of high neuronal cell body density (e.g., the mitral cell layer, data not shown). Despite this labeling of cells previously shown to express $\mathrm{S} 100 \mathrm{~B}$, it is noteworthy that not all CNS cells that labeled with anti-S100 antibody expressed GFP (data not shown).

\section{Microglia and subsets of Bergmann glia are labeled in some transgenic lines}

In contrast to the expected astrocytic labeling described above in mice of the Kosmos line, some of the YFP lines labeled distinct populations of cells in the CNS. Two clear examples emerged from an examination of the brains of YA and $\mathrm{YH}$ mice. In YA animals subsets of Bergmann glial cells in the cerebellum were brightly labeled (Fig. 8A), in contrast to Kosmos, in which all Bergmann glia appeared to be labeled. Both YA and YH mice had
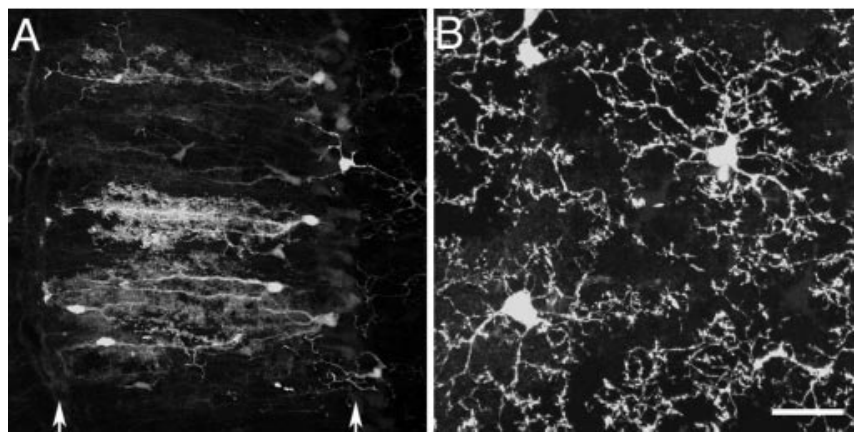

Figure 8. Some lines express FPs in subsets of glia in the CNS. A, Cerebellum of YA line showing bright YFP labeling of a subset of Bergmann glia in the molecular layer (between the arrows). $B$, Cortex of $Y A$ line showing labeling of microglia. Scale bar: $A, 20 \mu \mathrm{m} ; B, 10 \mu \mathrm{m}$.

bright labeling of ramified cells that were identified as microglia on the basis of their morphology, labeling with antibodies to the markers FA-11 and F4/80 (Ohmi et al., 2003) (supplemental Fig. $4 D-F$, available at www.jneurosci.org as supplemental material), and absence of labeling with GFAP (data not shown). In the cortex of YA mice, very little labeling was present that was not in microglia (Fig. 8 B), whereas in $\mathrm{YH}$ the microglia were present on a background of weaker labeling of astrocytes (supplemental Fig. $4 G$, available at www.jneurosci.org as supplemental material). Last, in addition to the labeling of spinal motor neurons described above, some YFP lines showed labeling of neurons in the brainstem. These cells have been shown previously to express S100B (cf. Friend et al., 1992; Yang et al., 1996).

\section{Discussion}

We report here the generation of transgenic mice that express fluorescent proteins under the control of the human S100B promoter. In many of the lines, expression occurs in the same cells in which the S100B protein itself is reportedly present, i.e., in Schwann cells, dendritic cells of the immune system, astrocytes, microglia, adipocytes, and some neurons in the brainstem. These results mirror some findings in a previous report in which $4.8 \mathrm{~kb}$ of mouse S100B regulatory sequence was used to drive expression of GFP (Vives et al., 2003). They also complement findings in which other promoters were used to drive transgenic expression of FPs in glial cells (Zhuo et al., 1997; Fuss et al., 2000; Nolte et al., 2001). However, we also found considerable variegation in transgene expression among the transgenic lines we generated. In some lines, cells in which the $\mathrm{S} 100 \mathrm{~B}$ protein is not normally found were clearly FP-positive. A prominent example is expression in spinal motor neurons. A second example is the presence of $\mathrm{YFP}+, \mathrm{S} 100-$ macrophages distributed throughout skeletal muscles. We also observed cases in which only some of the expected cell types were labeled. For example, in some of the lines microglial labeling was the most prominent labeling in the cortex. Still another type of variegation was labeling of subsets of a given cell type. Examples include Bergmann glia, peripheral Schwann cells, dendritic cells, macrophages, and $\alpha$ motor neurons. Thus, these lines present an array of labeling patterns.

Such variegation is not unusual in transgenic animals and has been attributed to variability in the site of transgene integration and methylation (silencing) as well as the absence in the transgene construct of some genomic sequences normally conferring control of the expression of the endogenous gene (Martin and Whitelaw, 1996). A transgenic mouse has been generated previously using a transgene containing $17.3 \mathrm{~kb}$ of sequence encoding human S100, including $9.0 \mathrm{~kb}$ of sequence upstream of the trans- 
lation start site and some $4 \mathrm{~kb}$ of sequence $3^{\prime}$ to the polyadenylation signal (Friend et al., 1992). These transgenic animals were reported to overexpress S100 appropriately in all cell types examined. The differences in transgene expression reported here and in this overexpression study could be explained by the improved sensitivity of a FP reporter over in situ hybridization. Differences between human and mouse promoter sequences also might explain some of the unexpected expression of FP we encountered. However, the variation among lines seen in our study was obtained using a single transgene and is therefore more likely to be caused by position effects. Whether FP expression in subsets of cells in any given line represents intrinsic differences among cells or is attributable to some chance occurrence during development remains unclear (cf. Feng et al., 2000).

Other investigators preparing transgenic mice have noted variegation like that reported here and have shown that this variegation can enable imaging of a small number of cells against a background of cells of the same type having no labeling (Walsh and Lichtman, 2003). The mice described here could be used to examine subsets of axons in muscles, Bergmann glial cells in the cerebellum, microglial cells in the cortex, blood-derived antigenpresenting cells (macrophages and dendritic cells), and Schwann cells in nerves and at synapses. In this study we have made initial attempts to understand the variegation in Schwann cell labeling at individual NMJs.

\section{Variegation in Schwann cell labeling at neuromuscular junctions}

The YFP label in Schwann cells follows an intriguing pattern in some of the lines. There is a high probability that, for any particular junction, either all of the TSCs express YFP or none of them do. Based on the presence of a similar expression pattern in early development, the presence of variegation in myelinating Schwann cells, and the association of both YFP+ and YFPSchwann cells with single axons, it seems unlikely that this pattern is dictated by motor neurons or muscle. Rather, the simplest explanation appears to be some type of random event during early development that results in Schwann cells or their progenitors becoming one of two types, YFP + or YFP-, with this commitment retained by daughter cells. Because the first Schwann cell to reach developing NMJs almost certainly arrives there by migration along an innervating axon and because the number of TSCs increases subsequently, at least in part, by cell division (cf. Love and Thompson, 1998), the first Schwann cell could serve as the founder for all the other TSCs as well as the Schwann cells that generate the myelin wrappings of the axon near the junction. Because multiple axons innervate fetal junctions, it is possible that different axons could recruit different potential founder Schwann cells to the same junction. To achieve the homogeneity seen at adult NMJs, the axon that survives synapse elimination would have to retain one of the sets of Schwann cells, possibly the Schwann cells that associated with it during development. Alternatively, the same founder Schwann cell and its descendants could populate a bundle of axons leading to each junction and separate these axons later in development, in the same way that Schwann cells migrate between and separate axons within developing nerve trunks (Peters and Muir, 1959). Inspection of the data in Figure 4 suggests that Schwann cells are almost as homogeneous at day 6 , when half the fibers in the muscle are polyneuronally innervated, as they are in the adult. However, at a stage when approximately half of the junctions are polyneuronally innervated and approximately half of the Schwann cells are YFP+, one would anticipate only a quarter more junctions with mixed
Schwann cell labeling than seen in the adult animal. Repeated, vital imaging in the neonate could be used to determine the relationship between the Schwann cells and axons that remain at NMJs after synapse elimination.

\section{Vital imaging reveals the stability of synaptic glia}

The original objective of this study was to produce mice useful for vital observation of TSCs at the NMJ. At least two of the lines (Kosmos and YG) appear useful in this regard because they have strongly labeled myelinating and terminal Schwann cells but little or no labeling of other cell types in the muscle. We have shown the feasibility of using these mice for vital imaging. Because few changes were found in the glia at imaged junctions, we believe that the imaging itself does not change the junctions. This result contrasts with the marked changes in Schwann cells observed in transgenic animals after denervation of the muscle (L. Tian, H. Kang, and W. J. Thompson, unpublished results), changes that are also seen in nontransgenic animals (cf. Son and Thompson, 1995a). Our observations extend to the glial components of the synapse the relative stability previously reported for the nerve terminal and postsynaptic apparatus at adult NMJs (Balice-Gordon and Lichtman, 1990). This finding contrasts with variability in glial cell numbers and positions observed during vital imaging of synapses in parasympathetic ganglia (Pomeroy and Purves, 1988), but these synapses are more dynamic than neuromuscular junctions.

We also found that TSCs send out short, unstable processes that explore the territory around the synapse (Robbins and Polak, 1988). These extensions may play an important role in matching TSC processes to nerve terminals and AChRs, should they happen to change. For example, as the junction grows during development, its glial coverings expand, with the addition of TSCs as required (Love and Thompson, 1998). The extension of longer TSC processes after denervation may represent an elaboration of these short, exploratory TSC processes. We are using these mice to follow the growth of these processes and to elucidate their role in nerve repair after full and partial denervation.

\section{References}

Allore RJ, Friend WC, O'Hanlon D, Neilson KM, Baumal R, Dunn RJ, Marks A (1990) Cloning and expression of the human S100 beta gene. J Biol Chem 265:15537-15543.

Astrow SH, Qiang H, Ko CP (1998) Perisynaptic Schwann cells at neuromuscular junctions revealed by a novel monoclonal antibody. J Neurocytol 27:667-681.

Balice-Gordon RJ, Lichtman JW (1990) In vivo visualization of the growth of pre- and postsynaptic elements of the neuromuscular junctions in the mouse. J Neurosci 10:894-908.

Balice-Gordon RJ, Lichtman JW (1993) In vivo observations of pre- and postsynaptic changes during the transition from multiple to single innervation at developing neuromuscular junctions. J Neurosci 13:834-855.

Balice-Gordon RJ, Lichtman JW (1994) Long-term synapse loss induced by focal blockade of postsynaptic receptors. Nature 372:519-524.

Brown MC, Jansen JKS, Van Essen D (1976) Polyneuronal innervation of skeletal muscle in new-born rats and its elimination during maturation. J Physiol (Lond) 261:387-422.

Castets F, Griffin WST, Marks A, Van Eldik LJ (1997) Transcriptional regulation of the human $S 100 \beta$ gene. Mol Brain Res 46:208-216.

Chalfie M, Tu Y, Euskirchen G, Ward WW, Prasher DC (1994) Green fluorescent protein as a marker for gene expression. Science 263:802-805.

Cocchia D, Michetti F, Donato R (1981) Immunochemical and immunocytochemical localization of S-100 antigen in normal human skin. Nature 294:85-87.

Cocchia D, Tiberio G, Santarelli R, Michetti F (1983) S-100 protein in "follicular dendritic" cells or rat lymphoid organs. An immunochemical and immunocytochemical study. Cell Tissue Res 230:95-103.

Feng G, Mellor RH, Bernstein M, Keller-Peck C, Nguyen QT, Wallace M, 
Nerbonne JM, Lichtman JW, Sanes JR (2000) Imaging neuronal subsets in transgenic mice expressing multiple spectral variants of GFP. Neuron 28:41-51.

Friedman B, Hockfield S, Black JA, Woodruff KA, Waxman SG (1989) In situ demonstration of mature oligodendrocytes and their processes: an immunocytochemical study with a new monoclonal antibody, rip. Glia 2:380-390.

Friend WC, Clapoff S, Landry C, Becker LE, O’Hanlon D, Allore RJ, Brown IR, Marks A, Roder J, Dunn RJ (1992) Cell-specific expression of high levels of human S100 beta in transgenic mouse brain is dependent on gene dosage. J Neurosci 12:4337-4346.

Fuss B, Mallon B, Phan T, Ohlemeyer C, Kirchhoff F, Nishiyama A, Macklin WB (2000) Purification and analysis of in vivo-differentiated oligodendrocytes expressing the green fluorescent protein. Dev Biol 218:259-274.

Ghandour MS, Langley OK, Labourdette G, Vincendon G, Gombos G (1981) Specific and artefactual cellular localizations of S 100 protein: an astrocyte marker in rat cerebellum. Dev Neurosci 4:66-78.

Gordon S, Lawson L, Rabinowitz S, Crocker PR, Morris L, Perry VH (1992) Antigen markers of macrophage differentiation in murine tissues. Curr Top Microbiol Immunol 181:1-37.

Grutzendler J, Kasthuri N, Gan WB (2002) Long-term dendritic spine stability in the adult cortex. Nature 420:812-816.

Hogan B, Beddington R, Constantini F, Lacy E (1994) Manipulating the mouse embryo, A Laboratory Manual, Ed 2. Cold Spring Harbor, NY: Cold Spring Harbor Press.

Huang WY, Aramburu J, Douglas PS, Izumo S (2000) Transgenic expression of green fluorescence protein can cause dilated cardiomyopathy. Nat Med 6:482-483.

Jiang H, Shah S, Hilt DC (1993) Organization, sequence, and expression of the murine S100beta gene: transcriptional regulation by cell type-specific cis-acting regulatory elements. J Biol Chem 268:20502-20511.

Koirala S, Qiang H, Ko CP (2000) Reciprocal interactions between perisynaptic Schwann cells and regenerating nerve terminals at the frog neuromuscular junction. J Neurobiol 44:343-360.

Lichtman JW, Magrassi L, Purves D (1987) Visualization of neuromuscular junctions over periods of several months in living mice. J Neurosci 7:1215-1222.

Love FM, Thompson WJ (1998) Schwann cells proliferate at rat neuromuscular junctions during development and regeneration. J Neurosci 18:9376-9385.

Lubischer JL, Thompson WJ (1999) Neonatal partial denervation results in nodal but not terminal sprouting and a decrease in efficacy of remaining neuromuscular junctions in rat soleus muscle. J Neurosci 19:8931-8944.

Ludwin SK, Kosek JC, Eng LF (1976) The topographical distribution of S-100 and GFA proteins in the adult rat brain: an immunohistochemical study using horseradish peroxidase-labelled antibodies. J Comp Neurol 165:197-207.

Martin DI, Whitelaw E (1996) The vagaries of variegating transgenes. Bioessays 18:919-923.

Michetti F, Dell'Anna E, Tiberio G, Cocchia D (1983) Immunochemical and immunocytochemical study of S-100 protein in rat adipocytes. Brain Res 262:352-356.

Michetti F, Rende M, Calogero G, Dell'Anna E, Cocchia D (1985) Immunochemical detection of S-100 protein in non-nervous structures of the rabbit eye. Brain Res 332:358-360.

Mizrahi F, Crowley JC, Shtoyerman E, Katz LC (2004) High-resolution in vivo imaging of hippocampal dendrites and spines. J Neurosci 24:3147-3151.

Monaco S, Gehrmann J, Raivich G, Kreutzberg GW (1992) MHC-positive, ramified macrophages in the normal and injured rat peripheral nervous system. J Neurocytol 21:623-634.

Mullen RJ, Buck CR, Smith AM (1992) NeuN, a neuronal specific nuclear protein in vertebrates. Development 116:201-211.

Nolte C, Matyash M, Pivneva T, Schipke CG, Ohlemeyer C, Hanisch UK, Kirchhoff F, Kettenmann H (2001) GFAP promoter-controlled EGFPexpressing transgenic mice: a tool to visualize astrocytes and astrogliosis in living brain tissue. Glia 33:72-86.

O’Malley JP, Waran MT, Balice-Gordon RJ (1999) In vivo observations of terminal Schwann cells at normal, denervated, and reinnervated mouse neuromuscular junctions. J Neurobiol 38:270-286.

Ohmi K, Greenberg DS, Rajavel KS, Ryazantsev S, Li HH, Neufield EF (2003) Activated microglia in cortex of mouse models of mucopolysaccharidoses I and IIIB. Proc Natl Acad Sci USA 100:1902-1907.

Peters A, Muir AR (1959) The relationship between axons and Schwann cells during development of peripheral nerves in the rat. J Exp Physiol 44:117-130.

Pomeroy SL, Purves D (1988) Neuron/glia relationships observed over intervals of several months in living mice. J Cell Biol 107:1167-1175.

Reddy LV, Koirala S, Sugiura Y, Herrera AA, Ko CP (2003) Glial cells maintain synaptic structure and function and promote development of the neuromuscular junction in vivo. Neuron 40:563-580.

Rich MM, Lichtman JW (1989) In vivo visualization of pre- and postsynaptic changes during synapse elimination in reinnervated mouse muscle. J Neurosci 9:1781-1805.

Robbins N, Polak J (1988) Filopodia, lamellipodia and retractions at mouse neuromuscular junctions. J Neurocytol 17:545-561.

Robitaille R (1998) Modulation of synaptic efficacy and synaptic depression by glial cells at the frog neuromuscular junction. Neuron 21:847-855.

Romani N, Holzmann S, Tripp CH, Koch F, Stoitzner P (2003) Langerhans cells: dendritic cells of the epidermis. APMIS 111:725-740.

Son Y-J, Thompson WJ (1995a) Schwann cell processes guide regeneration of peripheral axons. Neuron 14:125-132.

Son Y-J, Thompson WJ (1995b) Nerve sprouting in muscle is induced and guided by processes extended by Schwann cells. Neuron 14:133-141.

Stefansson K, Wollmann RL, Moore BW (1982) Distribution of S-100 protein outside the central nervous system. Brain Res 234:309-317.

Trachtenberg JT, Chen BE, Knott GW, Feng G, Sanes JR, Welker E, Svoboda $\mathrm{K}$ (2002) Long-term in vivo imaging of experience-dependent synaptic plasticity in adult cortex. Nature 420:788-794.

Vives V, Alonso G, Solal AC, Joubert D, Legraverend C (2003) Visualization of S100B-positive neurons and glia in the central nervous system of EGFP transgenic mice. J Comp Neurol 457:404-419.

Walsh MK, Lichtman JW (2003) In vivo time-lapse imaging of synaptic takeover associated with naturally occurring synapse elimination. Neuron 37:67-73.

Yang Q, Hamberger A, Khatibi N, Stigbrand T, Haglid KG (1996) Presence of S-100 beta in cholinergic neurones of the rat hindbrain. NeuroReport 7:3093-3099.

Zhou L, Sun B, Zhang CL, Fine A, Chiu SY, Messing A (1997) Live astrocytes visualized by green fluorescent protein in transgenic mice. Dev Biol 187: 36-42. 